\title{
Nota sobre a Distinção entre Obrigação, Dever e ônus
}

Eros Roberto Grau

Professor Adjunto da Faculdade de Direito da Universidade de Săo Paulo

01. - A linguagem jurídica é construída, fundamentalmente, mediante a apropriação de palavras e expressões da linguagem natural. Ao contrário dos especialistas em outras ciências, não desfrutamos da vantagem de criar palavras novas, artificiais, como termos dos conceitos com os quais trabalhamos.

Por isso, a linguagem jurídica, tal como a natural, é marcantemente ambigua e imprecisa - o que lhe confere uma textura aberta ${ }^{1}$.

As situações de imprecisão - que se manifestam quando não há limites precisos do campo de significação a que corresponde a palavra ou expressão - leva o jurista ao necessário exame dos chamados conceitos indeterminados, abertos ou práticos. As de ambiguiidade que se manifestam quando a mesma palavra ou expressão assume, em contextos distintos, diversos significados - impele-nos ao tratamento dos chamados conceitos plurissignificativos. O horizonte de indagações que desde aí se abre nos conduz às questões da discricionariedade e da interpretação.

É certo que tais circunstâncias findam, inúmeras vezes, por comprometer o perfeito entendimento das noçōes jurídicas. Mas assim tem de ser, imperiosamente, visto que o requisito da generalidade das leis reclama o uso de linguagem caracterizada - repita-se - por textura aberta. Daí porque, por razões não apenas de ordem política, mas também de índole jurídica, todo o casuísmo normativo deve ser repudiado.

Não pretendo, nas linhas que seguem, desenvolver considerações a propósito dos inúmeros problemas que a ocupação detida com as

1. Vide GENARO CARRI6, Notas sobre Derecho y Lenguage, segunda edicion, Abelardo Perrot, Buenos Aires, 1979, págs. 27 e ss. 
palavras e expressões jurídicas enseja - que passam desapercebidas quando simplesmente as usamos, sem maiores preocupações com as suas significações - mas, tão somente, a partir da verificação de que são ambíguos os termos obrigação e dever, introduzir algumas ponderações sobre a noção jurídica de ônus, vocábulo também ambíguo.

02. - O termo obrigação, como adverte MANUEL A. DOMINGUES $\mathrm{DE}$ ANDRADE ${ }^{2}$, é usado, em sentido amplo, na linguagem jurídica, como sinônimo de dever jurídico ou como incluindo também a noção de sujeição. Cumpre-nos, pois, inicialmente, discernir os sentidos que se designam sob tais vocábulos.

A sujeição, na colocação de CARNELUTTI ${ }^{3}$, é a expressão subjetiva do comando jurídico, considerado no seu lado passivo, isto é, da parte de quem é comandado; significa necessidade de obedecer. Pelo lado ativo, o comando jurídico se realiza, enquanto expressão subjetiva, em poder. Está em situação de sujeição, pois, quem quer que esteja colocado no lado passivo, em relação àquele ao qual o comando tenha atribuído um poder jurídico. Nela se situa, por exemplo, o mandatário, quando decida o mandante revogar a outorga expedida. O mandatário, em situação de sujeição, há de obedecer, suportando os efeitos da revogação.

Distinguindo a sujeição do dever, CARNELUTTI ${ }^{4}$ aponta que este é um vínculo imposto à vontade, ao passo que aquela significa impossibilidade de querer com eficácia.

O dever jurídico consubstancia precisamente uma vinculação ou limitação imposta à vontade de quem por ele alcançado. Definido como tal pelo ordenamento jurídico, o dever há de ser compulsoriamente cumprido, sob pena de sanção jurídica - o seu não atendimento configura comportamento ilícito.

Aspecto fundamental, a aproximar a sujeicão do dever - porque comum à essência de ambos - é o referido à circunstância de que tanto um quanto o outro são impostos em razão da tutela de interesses alheios aos dos sujeitos por eles alcançados. À consideração de tal aspecto adiante retornarei.

A obrigação - tomado o vocábulo em sentido estrito - supõe uma situação de dever, em que se coloca o devedor. Não obstante, é certo que o conceito de dever transcende o âmbito do direito das obrigações: há deveres jurídicos que não compreendem ohrigação de rienhuma espécie. Assim, v.g., com relação ao dever, de todos, de abstenção da prática de condutas definidas como crimes ${ }^{5}$.

2. Teoria Geral das Obrigações, 3a edição, Livraria Almedina, Coimbra, 1966, pág. 1.

3. Sistema di Diritto Processuale Civile, vol. I, CEDAM, Padova, 1936, pág. 51.

4. Ob. e loc. cits.

5. Neste sentido ANDREAS von THUR. Tratado de las Obligaciones. trad. de W. Roces, tomo I, Editorial Reus S/A., Madrid, 1934, pág. 5. No exame do pensamento 
03. - O termo obrigação, pois, como vimos, é em sentido amplo usado para designar o elemento passivo de qualquer relação jurídica ${ }^{6}$. Cumpre neste passo, pois, discernir o seu significado em sentido estrito, quando a palavra obrigação passa a constituir o termo próprio de uma classe de relações jurídicas - a obrigacional — que se coloca em paralelo à dos direitos reais, à dos direitos de família e à dos direitos de sucessão?

Neste sentido, estrito, a obrigação 'consubstancia' um vínculo em razão do qual uma pessoa (devedor) deve a outra (credor) o cumpri.mento de uma certa prestação. A obrigação consubstancia um direito relativo, na medida em que o crédito que dela decorre apenas pode ser exigido, pela pessoa ou pluralidade de pessoas dele titular, contra a pessoa ou pluralidade de pessoas na situação de devedor. Aí a distinção fundamental entre bbrigação e direito real: este pode ser exigido erga omnes. De outra parte, diz-se também constituir, a obrigação, um direito pessoal, conquanto que, descumprido o dever de prestação, a sua execução forçada ou providência que a substitua só é exigível por iniciativa do credor; de toda sorte, é certo que o devedor tem, perante o credor, um dever sancionado pelo Direito.

Qualquer que seja a concepção - monista ou dualista - que se adote em relação à obrigação, há de ser ela entendida como modalidade específica de dever jurídico. Apenas, no segundo caso, da concepção dualista, ao lado da sub-relação de dever (Schuld), remanesce outra sub-relação (Haftung), de responsabilidade, que coloca o devedor em situação análoga à de sujeição.

Podemos, pois, ter que - tal como no dever - na obrigação, o cumprimento da prestação, pelo devedor, importa atendimento de interesse, o alheio, isto é, do credor. O descumprimento da prestação, por outro lado, é juridicamente sancionado.

Assim ocorre na relação jurídico-tributária, que é de natureza obrigacional: o pagamento do tributo, pelo particular, implica satisfaçâo de interesse do Estado.

04. - Atribui-se a BRUNETTI a primeira teorização a respeito do onus ${ }^{8}$. Inicialmente, em seu Il delito civile (1960), a seguir em seu Norme e regole finali nel diritto (1913), BRUNETTI postula o entendi-

de von THUR, vali-me também de seu Allgemeiner Teil des Schweizeischen Obligationrechts, na tradução francesa de Maurice de Torrenté e Emile Thilo (Partie Generale du Code Féderal des Obligations, vol. I, deuxiême edition, Imprimerie Centrale S/A., Lausanne, 1933).

6. Cf. MANUEl A. DOMINGUES DE ANDRADE, ov. cit., pág. 5.

7. Idem, ibidem MANUEL A. DOMINGUES DE ANDRADE refere ainda outras classes de relações jurídicas; a dos direitos de personalidade, a dos direitos sobre bens imateriais e a dos direitos corporativos, que se integra na teoria das pessoas coletivas ou na das sociedades (obrigações).

8. Cf. OBERDAN TOMMASO SCOZZAFAVA, Onere (nozione), in Enciclopedia del Diritto, Giuffré Editore, vol. XXX, págs. 100/10. 
mento de que nem todas as normas jurídicas tem caráter imperativo. Segundo ele, há uma categoria delas - a das normas finais - que disciplina de modo não imperativo a conduta humana ${ }^{9}$. Segundo BOBBIO, tais normas são precisamente os imperativos hipotéticos ou normas técnicas de KANT ${ }^{10}$. Ao seu descumprimento é conseqüente não a aplicação de uma sanção jurídica ao sujeito, mas o não alcance de uma determinado fim pretendido pelo sujeito. No caso, a norma final, segundo BRUNETTI, estabelece o que ele denomina um dever livre, distinto do dever que resulta dos imperativos propriamente ditos.

A teorização de BRUNETTI, que leva à construção da noção ônus, foi abandonada, em parte em razão de ter sido iradequadamente estendida a hipóteses às quais não se pode amoldar, tais como a das relações de natureza obrigacional. $\hat{\mathrm{E}}$ óbvio que, aí, não cabe qualquer alusão a dever livre ou ônus, visto como o sujeito que cumpre a prestação obrigacional não o faz para evitar as conseqüências do inadimplemento, mas age na conformidade de uma imposição normativa. Daí porque, aliás, a expressão dever livre é contraditória: a noção de dever supõe atuação no interesse alheio; por isso que o sujeito passivo do dever está por ele vinculado e dele não pode dispor, como se estivesse ele referido ao seu próprio interesse ${ }^{11}$.

$\mathrm{E}$ exato, porém, que Von THUR ${ }^{12}$ apontava o fato de a palavra deve ser usada sem grande precisão técnica, nos casos em que a lei condiciona a um ato a aquisição ou perda de um direito. E toma dos exemplos do "dever", que tem o lesionado, de evitar ou minimizar o dano e do "dever", que tem o credor, de denunciar seu crédito em caso de concurso de credores. A realização de tais atos, todavia argumentava Von THUR - não é expressão do cumprimento de um dever, mas sim de incumbências (Obliegenheiten) que cabem ao sujeito. O cumprimeito de tais "deveres" consubstancia gestão de um interesse pessoal, para que se evite a perda de um direito.

Este, precisamente, o ponto fundamental desde cuja colocação se torna possível a completa compreensão da noção de ônus.

05. - Foi CARNELUTTI, no entanto, quem de modo mais completo colocou as linhas acabadas da noção de ônus. Segundo ele, falamos de ônus quando o exercício de uma faculdade é definido como condição para a obtenção de uma certa vantagem; para tanto, o ônus é uma faculdade cujo exercício é necessário para a realização de um

9. Vide, a propósito, OBERDAN TOMMASO SCOZZAFAVA, ob. cit., pág. 101; NORBERTO BOBBIO, Teoria della Norma Giuridica, G. Giapichelli, Torino, 1958, págs. 160/164; GIAN ANTONIO MICHEL, L'Onere della prova, CEDAM, Padova, 1966, págs. 63/65.

10. Ob. cit., pág. 160.

11. Uma crítica mais incisiva à postulação de BRUNETTI, em torno do dever livre, é desenvolvida por BOBBIO, ob. cit., págs. 163/164.

12. Tratado de las Obligaciones, cit., págs. 4/5 e Partie Generale du Code Féderal des Obligations. cit., págs. 9/10. 
interesse ${ }^{13}$. E esclarece: dever e ônus têm em comum o elemento formal, consistente no vínculo à vontade, mas diverso o elemento substancial, porque o vínculo é imposto, quando se trata de dever, no interesse alheio, e, tratando-se de ônus, para a tutela de um interesse próprio ${ }^{14}$.

O ônus, dest'arte, é um vínculo imposto à vontade do sujeito em razão do seu próprio interesse. Nisto se distingue do dever - e da obrigação - que consubstancia vínculo imposto àquela mesma vontade, porém no interesse de outrem. Por isso que o não-cumprimento do ônus não acarreta, para o sujeito, sanção jurídica, mas tão-somente uma certa desvantagem econômica: a não obtenção da vantagem, a não satisfação do interesse ou a não realização do direito pretendido. Já o não-cumprimento do dever — ou da obrigação — acarreta sanção jurídica para o sujeito. Neste último caso, o interesse a cuja tutela aproveita o cumprimento do dever é alheio à pessoa do sujeito a ele vinculado; no primeiro caso, o interesse a que respeita a vinculação pelo ônus é do próprio sujeito vinculado.

Descreve-se o ônus, assim, como o instrumento através do qual o ordenamento jurídico impõe ao sujeito um determinado comportamento, que deverá ser adotado se não pretender ele arcar com conseqüências que lhe serão prejudiciais ${ }^{15}$. Ou como um comportamento que o sujeito deve adotar para alcançar uma determinada vantagem, que consiste na aquisição ou na conservação de um direito ${ }^{16}$.

CARNELUTTI retorna à distinção entre dever e ônus ao colocar as noções de ato deviāo e ato necessário ${ }^{17}$ : ato devido é aquele que o direito objetivo impõe na tutela de interesse alheio; ato necessário, o que o direito objetivo exige de quem quer conseguir um certo fim, correspondente ao seu próprio interesse. No primeiro caso, o dever; no segundo, o ônus.

06. - Dos ônus - ou incumbências - trata a doutrina alemã, sob a designação de Obliegenheiten. A exposição de KARL LARENZ ${ }^{18}$, a propósito delas - que passo a reproduzir é extremamente expressiva. As Obliegenheiten, segundo ele, devem ser distinguidas dos deveres jurídicos Rechtspflichten. Ãquelas correspondem condutas cujo cumprimento se verifica basicamente no interesse daqueles de

13. Ob. cit., pág. 55 .

14. Idem, ibidem.

15. Cf. OBERDAN TOMMASO SCOZZAFAVA, ob. cit., pág. 109.

16. Cf. GIUSEPPE DE STEFANO, Onere (dir. proc. civ.), in Enciclopedia del Diritto, Giuffré Editore, vol. XXX, pág. Vide também, a propósito da noção de ônus, além da exposição de MANUEL A. DOMINGUEES DE ANDRADE, ob, cit., págs. 3/5, HALUK TANDOGAN, Notions Préliminaires a la Thoerie Générale des Obligations, Librairie đe L'Université - Georg \& Cie S.A., Genéve, 1972, págs. 28/29.

17. Ob. cit., vol. II, 1938, págs. 73 e 84 .

18. Allgemeiner Teil des Bürgerlichen Rechts, Verlang C.H. Beck, München, 1967, págs. $223 / 224$. 
quem foram elas exigidas. Podemos referi-las, segundo REIMER SCHMIDT, como deveres de menor intensidade ou, segundo ENNECCERUS - NIPPERDEY, como encargos que podem ser exigidos de um sujeito jurídico também no interesse de outro, sem que este outro, contudo, possa impor à parte por eles vinculada o seu cumprimento. O característico é que o ordenamento jurídico, neste caso, deixa o sujeito livre de qualquer coação e também de qualquer dever de indenização, na hipótese de não-cumprimento da exigência, contentando-se, em vez disso, com sanções mais amenas. Essa sanção mais amena geralmente consiste na perda de uma melhor posição jurídica ou em outra desvantagem jurídica qualquer. Disso se deduz que há distinção entre o descumprimento da Obliegenheit e o descumprimento de um dever. $\mathrm{O}$ ordenamento jurídico não impõe o cumprimento da Obligenheit como um dever, categoricamente, mas apenas hipoteticamente. Quando a pessoa vincula pela Obliegenheit deseja evitar a desvantagem, deve cumprir a prestação que àquela corresponde; se não desejar cumpríla, tem de se conformar com uma certa desvantagem jurídica, sem que ninguém possa porém censurá-lo por ter ele se conduzido contra a lei.

07. - Postas tais noções, poderemos distinguir de um lado o dever - e a obrigação - como vínculo imposto à vontade do sujeito em razão da tutela de interesse alheio e cujo descumprimento compreende um ilícito, importando a aplicação de sanção jurídica; de outro o ônus como vínculo imposto à vontade do sujeito como condição para a satisfação do seu próprio interesse e cujo descumprimento não importa a aplicação de sanção jurídica, mas tão-somente efeitos econômicos negativos.

A lei que estabelece o ônus não impõe a adoção de uma conduta pelo sujeito a ele vinculado, isto é, não fixa dever de conduta. Por isso não é dever; não se confunde nem com o dever, nem com a obrigação. Ao sujeito por ele vinculado não se impc̃e a adoção da conduta definida pelo ônus; resta-lhe a opção de não cumprí-la, se para tanto desistir da obtenção ou conservação de um direito. Pretendendo obtê-lo ou conservá-lo, todavia, há de necessariamente adotar aquela conduta, cujo cumprimento é condição para tal obtenção ou conservação.

Visualizando hipóteses nas quais o objeto do ônus configura prestações de dar - a caução para participação de licitação pública e o depósito compulsório para viagem ao exterior - teremos que ninguém está juridicamente compelido a participar de tais licitações ou a viajar ao exterior. Se, porém, alguém pretender fazer uso de tais direitos, ficará sujeito - mas tão-somente neste caso - ao pagamento da caução ou do depósito. Em ambas as hipóteses estamos diante de ônus que compreendem prestação de dar. O seu cumprimento respeita à satisfação não de interesse alheio, mas dos próprios sujeitos vinculados pelo ônus. O não-cumprimento do ônus não consubstancia ilícito e, portanto, não importa a aplicação de sanções jurídicas àqueles sujeitos. $O$ único efeito decorrente daquele não-cumprimento se 
expressa em termos de desvantagem decorrente da impossibilidade de participação na licitação e da viagem ao exterior. Os sujeitos em questão, vinculados por ônus, nem por isso estão compelidos ao pagamento da prestação de dar (a) e à participação em licitação ou à viagem ao exterior (b).

Insisto em que inteiramente diversas destas são as situações em que se colocam sujeltos vinculados por dever (uever legab) ou por ourigaçao (aever obrigaciona ). ' 'oda a gente esta juridicamente compelicia a nao turbar a propriedade alheia - aí um dever. Quem quer que contrate com outrem, estando na situação de devedor, está juridicamente compelido a cumprir o objeto da obrigação; quem quer que desenvolva atividade economica sujeita a tributaçao esta juridicamente compelido a pagar imposto, a partir da formalização do lançamento, conseqüente à verificação do tato gerador - aqui, nestes dois últimos casos, a obrigação, contratual e tributária. O mesmo, também, ocorre na hipótese de obrigação tributária que tenha por objeto o pagamento de taxa. Nela, o sujeito deve usar um determinado serviço público - mesmo porque os remunerados por taxa são serviços públicos compulsórios - ou desenvolve atividade sujeita a poder de polícia. Caracterizado aquele uso ou o exercício de tal atividade, surge a obrigação de pagamento da taxa. Os sujeitos em questão, em todas essas hipóteses, vinculados por dever ou obrigação, estão juridicamente compelidos ao cumprimento de seus respectivos objetos.

08. - Sopesadas as observações acima alinhadas, poderemos referir o ônus como vínculo que a lei impõe à vontade do sujeito como condição à obtenção ou conservação; pelo próprio sujeito, de um interesse seu; neste sentido, na dicção de Von THUR ${ }^{19}$, o ônus é expressão da gestão de um interesse pessoal; o sujeito vinculado pelo ônus não está juridicamente compelido a cumprir o seu objeto, tal como ocorre no dever e na obrigação; o seu não-cumprimento não implica imposição de sanção jurídica ao sujeito vinculado pelo ônus, mas tão-somente a não obtenção ou não conservação de um direito.

Atribuo à exposição desenvolvida uma única virtude: a de deixar bem definidas as significações a serem, no nível jurídico, conferidas a palavras cuja ambigüidade, por vezes, perturba irremediavelmente o entendimento de textos jurídicos, seja normativos, seja doutrinários. Se, a partir do consenso a respeito de tais significações - ou de outras que, de modo mais correto, se proponha -, passarmos a usá-las segundo tal convenção, por certo estaremos contribuindo para a maior clareza da comunicação jurídica.

19. Tratado de las Obligaciones, cit., págs. 5 e Partie Génerale du Code Féderal des Obligations, cit., pág. 9. 